6 Weinberger DM, Harboe ZB, Sanders EA, et al. Association of serotype with risk of death due to pneumococcal pneumonia: a meta-analysis. Clin Infect Dis 2010; 51: 692-699.

7 Naucler P, Darenberg J, Morfeldt E, et al. Contribution of host, bacterial factors and antibiotic treatment to mortality in adult patients with bacteraemic pneumococcal pneumonia. Thorax 2013; 68: 571-579.

8 Vernatter J, Pirofski LA. Current concepts in host-microbe interaction leading to pneumococcal pneumonia. Curr Opin Infect Dis 2013; 26: 277-283.

9 Weinberger DM, Trzcinski K, Lu Y-J, et al. Pneumococcal capsular polysaccharide structure predicts serotype prevalence. PLoS Pathog 2009; 5: e1000476.

10 Weiser JN, Kapoor M. Effect of intrastrain variation in the amount of capsular polysaccharide on genetic transformation of Streptococcus pneumoniae: implications for virulence studies of encapsulated strains. Infect Immun 1999; 67: 3690-3692.

11 Sanchez CJ, Hinojosa CA, Shivshankar P, et al. Changes in capsular serotype alter the surface exposure of pneumococcal adhesins and impact virulence. PLoS One 2011; 6: e26587.

12 Klemets P, Lyytikainen O, Ruutu P, et al. Invasive pneumococcal infections among persons with and without underlying medical conditions: implications for prevention strategies. BMC Infect Dis 2008; 8: 96.

13 Marrie TJ, Wu L. Factors influencing in-hospital mortality in community-acquired pneumonia: a prospective study of patients not initially admitted to the ICU. Chest 2005; 127: 1260-1270.

14 Aspa J, Rajas O, Rodriguez de Castro F, et al. Impact of initial antibiotic choice on mortality from pneumococcal pneumonia. Eur Respir J 2006; 27: 1010-1019.

15 Martinez JA, Horcajada JP, Almela M, et al. Addition of a macrolide to a beta-lactam-based empirical antibiotic regimen is associated with lower in-hospital mortality for patients with bacteremic pneumococcal pneumonia. Clin Infect Dis 2003; 36: 389-395.

\title{
Risk factors for the misdiagnosis of tuberculosis in the UK, 2001-2011
}

\author{
To the Editor:
}

In the past 20 years, following several decades of decline, the number of tuberculosis (TB) cases in the UK has increased. The characteristics of TB cases have changed, from a disease that was predominantly pulmonary and widespread in the population [1], to one that is concentrated in major urban areas affecting immigrants, the homeless, prisoners and drug users [2], with a high proportion of extrapulmonary disease [3]. The signs and symptoms of TB are shared with many other diseases. Therefore, knowledge of the epidemiology of TB and current associated risk factors is essential in informing a diagnosis [4].

In this analysis, the demographic characteristics of misdiagnosed cases (those notified and subsequently denotified) were compared with those correctly diagnosed at the outset. Knowledge of these details may inform improved clinical management of patients presenting with symptoms from the differential diagnosis in which TB and other diseases are included.

The Public Health England Enhanced Tuberculosis Surveillance (ETS) System collects demographic and clinical data on TB cases in England, Wales and Northern Ireland. The definition of TB used by ETS is based either on a positive culture of Mycobacterium tuberculosis complex in a clinically ill patient or on clinical and/or radiological signs and/or symptoms compatible with TB, together with a clinician's decision to treat the patient with a full course of anti-tuberculosis therapy. Cases may subsequently be denotified if found not to be TB on further investigation. Follow-up information on treatment outcome is requested 12 months after commencement and includes a prompt for denotification of the case if appropriate.

All cases notified between 2001 and 2011 were included in the analysis. Cases were identified as "true" TB cases (any TB case reported to ETS that was not subsequently denotified or reported as not having had TB at the 12-month treatment outcome follow-up), or "misdiagnosed" cases (any case that was subsequently denotified or reported as not having had TB at the 12-month treatment outcome follow-up).

Data were analysed using Stata V.13.1 (StataCorp, College Station, TX, USA). Risk factors included in the analyses were: sex, age group, location, ethnicity, place of birth (UK- or non-UK-born), site of disease, history of TB and time from entry to the UK until TB diagnosis. Logistic regression was used to obtain odds ratios, and variables associated with the outcome at $\mathrm{p}<0.05$ in the univariable analysis were considered for multivariable analysis in a forward stepwise fashion, starting with the ones most strongly associated with the outcome. The category with the lowest risk of misdiagnosis was used as the baseline. Statistical significance 
of main effects was assessed by means of likelihood ratio test with p-values of $<0.05$ deemed significant. Possible interactions and plausibility were considered, with stratified results reported as appropriate.

The total number of cases reported between 2001 and 2011 was 92976 . Of these, 10053 (10.81\%) were subsequently identified as misdiagnosed; 9745 were proactively denotified and 308 were reported as not having had TB at the 12-month treatment outcome follow up. The number of misdiagnosed cases increased significantly between 2001 and 2011 ( $p<0.001)$.

In the fully adjusted model, for all variables, except sex, there was strong evidence of an association with misdiagnosis (table 1). Using the Indian ethnic group as the baseline, the white ethnic group had 2.15 times (95\% CI 1.91-2.43) the odds of misdiagnosis, with increased odds also observed in the black African (OR 1.31, 95\% CI 1.17-1.47), Bangladeshi (OR 1.55, 95\% CI 1.29-1.86) and other ethnic groups (OR 1.48, 95\% CI 1.32-1.66).

There was strong evidence of an interaction between age group and site of disease (likelihood ratio test $\mathrm{p}<0.0001)$. Among pulmonary cases, the risk of misdiagnosis was higher in older adults compared to young adults. Those aged 45-64 years with pulmonary disease had higher odds of misdiagnosis compared to those aged 15-44 years, irrespective of their sputum smear status (positive: OR 2.70, 95\% CI 2.21-3.30; negative or unknown: OR 1.41, 95\% CI 1.18-1.67).

Those aged 65 years and over remained at increased risk of misdiagnosis for both pulmonary and extrapulmonary sites of disease, but the effect was greater for pulmonary disease and positive sputum smear status (OR 3.7, 95\% CI 2.99-4.51, and OR 1.46, 95\% CI 1.27-1.68, respectively, with $\mathrm{p}<0.0001$ ). The highest risk of misdiagnosis of extrapulmonary $\mathrm{TB}$ was in children, who were twice as likely to be misdiagnosed than young adults (OR 2.18, 95\% CI 1.84-2.61).

There was no statistical evidence of interaction between ethnicity and place of birth/time since UK entry to TB diagnosis and between the latter and site of disease/sputum smear status.

Our findings show that TB misdiagnosis was most likely in those born in the UK, aged 45 years and over, of white ethnicity and with sputum smear positive pulmonary disease.

These findings are consistent with the observation that the incidence of TB is particularly high among people born in countries with a high TB burden, from ethnic minority groups and in patients aged 15-44 years. The reduction in TB incidence over the past century has inevitably decreased the opportunity for clinicians in low incidence areas to gain experience and knowledge of the common presentations of TB and its changing epidemiology. This in turn may have resulted in misplaced suspicion and hence misdiagnosis. In low incidence settings, there is a clinical conundrum as many patients with symptoms of TB may not have the disease; at the same time, ignoring warning signs even in a low risk person can result in delayed diagnosis and potential outbreaks.

Misdiagnosis of TB is problematic both for individuals and for the wider community. For patients, the impact of misdiagnosis would include not being treated for the condition or infection they actually have, and also in the meantime undergoing prolonged anti-tuberculosis therapy, with its known potential adverse effects, some of which can be serious. Such wrongly diagnosed individuals may also find themselves subject to the stigma that still sometimes comes with TB diagnosis. For the wider community, there are the financial costs of unnecessary contact tracing and investigation as well as inappropriate prophylaxis. There may also be the psychological costs of anxiety amongst people who believe themselves exposed to infection. Where the true diagnosis is infectious to others, the undiagnosed infection may spread while the focus is erroneously on TB.

A limitation of this study is the regional variation in denotification due to differences in clinical practice and data collection systems. This would reduce the number of cases with the outcome of interest, but it is unlikely that these cases would have different characteristics than those that were included in this analysis. A further limitation is the lack of detailed clinical information to determine the appropriateness of diagnosis in each of these, and furthermore we do not have data on the certainty of the diagnosis in those who were successfully treated without bacteriological confirmation. Atypical mycobacterial infection accounted for $7.2 \%$ of all the misdiagnosis cases in the study period. This study also does not consider misdiagnosis where a true diagnosis of TB is missed. New, rapid and accurate tests for the diagnosis of TB are warranted to help clinicians make a prompt and appropriate judgement.

The inclusion of TB in the differential diagnosis of patients with signs and symptoms suggestive of TB is absolutely essential. This analysis aims to inform clinicians of the characteristics of patients who are ultimately denotified so as to encourage prompt and appropriate investigations are made in this group to attempt to rule in $\mathrm{TB}$ or to make a definitive alternative diagnosis. 
TABLE 1 Descriptive, univariable and multivariable analysis of the numbers of initially reported tuberculosis (TB) cases subsequently misdiagnosed, in England, Wales and Northern Ireland, 2001-2011, and association between age group and the misdiagnosis of TB, stratified by site of disease/sputum-smear status

\begin{tabular}{|c|c|c|c|c|c|c|c|c|c|c|c|c|c|c|c|c|}
\hline \multirow[t]{2}{*}{ Variable } & \multirow[t]{2}{*}{$\begin{array}{l}\text { Misdiagnosed } \\
\mathrm{n}[\%]\end{array}$} & \multirow[t]{2}{*}{$\begin{array}{l}\text { Unadjusted } \\
\quad \text { OR }\end{array}$} & \multirow[t]{2}{*}{$95 \% \mathrm{Cl}$} & \multirow[t]{2}{*}{$\mathrm{p}$-value } & \multirow[t]{2}{*}{$\begin{array}{l}\text { Adjusted } \\
\text { OR }\end{array}$} & \multirow[t]{2}{*}{$95 \% \mathrm{Cl}$} & \multirow[t]{2}{*}{ p-value } & \multicolumn{3}{|c|}{ Pulmonary/SS+ } & \multicolumn{3}{|c|}{$\begin{array}{l}\text { Pulmonary/SS- } \\
\text { or unknown }\end{array}$} & \multicolumn{3}{|c|}{ Extrapulmonary } \\
\hline & & & & & & & & OR & $95 \% \mathrm{Cl}$ & $p$-value & OR & $95 \% \mathrm{Cl}$ & $p$-value & OR & $95 \% \mathrm{Cl}$ & $\mathrm{p}$-value \\
\hline Overall & 10053 (10.81) & & & & & & & & & & & & & & & \\
\hline Sex & & & & 0.1 & & & 0.05 & & & & & & & & & \\
\hline Male & 5594 (10.41) & 1.04 & $0.99-1.08$ & & 0.94 & $0.89-0.99$ & & & & & & & & & & \\
\hline Female & 4367 (10.77) & Ref. & & & Ref. & & & & & & & & & & & \\
\hline Age group & & & & $<0.0001$ & & & $<0.0001$ & & & & & & & & & \\
\hline $0-14$ years & 995 (18.02) & 3.10 & $2.89-3.36$ & & 2.12 & $1.77-2.54$ & & 0.25 & $0.10-0.62$ & 0.003 & 0.3 & $0.22-0.38$ & $<0.001$ & 2.18 & $1.84-2.61$ & $<0.001$ \\
\hline $15-44$ years & 3591 (6.59) & Ref. & & & Ref. & & & Ref. & & & Ref. & & & Ref. & & \\
\hline 45-64 years & 2479 (13.13) & 2.14 & $2.03-2.26$ & & 1.16 & $1.01-1.34$ & & 2.70 & $2.21-3.30$ & $<0.001$ & 1.41 & $1.18-1.67$ & $<0.001$ & 1.32 & $1.17-1.50$ & $<0.001$ \\
\hline$\geqslant 65$ years & 2980 (19.48) & 3.43 & $3.35-3.61$ & & 1.31 & $1.13-1.53$ & & 3.70 & $2.99-4.51$ & $<0.001$ & 1.55 & $1.29-1.85$ & $<0.001$ & 1.46 & $1.27-1.68$ & $<0.001$ \\
\hline Region & & & & $<0.0001$ & & & $<0.0001$ & & & & & & & & & \\
\hline East Midlands & 872 (13.57) & 2.01 & $1.85-2.19$ & & 1.44 & $1.28-1.61$ & & & & & & & & & & \\
\hline East of England & 599 (11.55) & 1.67 & $1.52-1.83$ & & 1.19 & $1.05-1.34$ & & & & & & & & & & \\
\hline London & 2775 (7.25) & Ref. & & & Ref. & & & & & & & & & & & \\
\hline North East & $155(8.32)$ & 1.16 & $0.98-1.37$ & & 0.63 & $0.51-0.77$ & & & & & & & & & & \\
\hline North West & $737(8.66)$ & 1.21 & $1.11-1.32$ & & 0.89 & $0.80-0.99$ & & & & & & & & & & \\
\hline South East & 1383 (16.45) & 2.52 & $2.35-2.70$ & & 1.58 & $1.43-1.74$ & & & & & & & & & & \\
\hline South West & $394(12.06)$ & 1.75 & $1.57-1.96$ & & 0.89 & $0.76-1.03$ & & & & & & & & & & \\
\hline West Midlands & 1998 (16.81) & 2.58 & $2.43-2.75$ & & 1.23 & $1.11-1.35$ & & & & & & & & & & \\
\hline $\begin{array}{l}\text { Yorkshire and the } \\
\text { Humber }\end{array}$ & $754(10.23)$ & 1.46 & $1.26-1.55$ & & 0.92 & $0.82-1.03$ & & & & & & & & & & \\
\hline Northern Ireland & 98 (11.98) & 1.74 & $1.40-2.16$ & & 0.45 & $0.36-0.57$ & & & & & & & & & & \\
\hline Wales & 288 (12.97) & 1.91 & $1.67-2.17$ & & 0.70 & $0.55-0.90$ & & & & & & & & & & \\
\hline Ethnic group & & & & $<0.0001$ & & & $<0.0001$ & & & & & & & & & \\
\hline White & 4313 (19.37) & 3.81 & $3.55-4.08$ & & 2.15 & $1.91-2.43$ & & & & & & & & & & \\
\hline Black African & 1188 (6.22) & 1.05 & $0.96-1.14$ & & 1.31 & $1.17-1.47$ & & & & & & & & & & \\
\hline Indian & 1124 (5.93) & Ref. & & & Ref. & & & & & & & & & & & \\
\hline Pakistani & $943(7.09)$ & 1.21 & $1.11-1.32$ & & 0.90 & $0.79-1.02$ & & & & & & & & & & \\
\hline Bangladeshi & $255(8.11)$ & 1.40 & $1.21-1.61$ & & 1.55 & $1.29-1.86$ & & & & & & & & & & \\
\hline Other & 1007 (7.89) & 1.36 & $1.24-1.48$ & & 1.48 & $1.32-1.66$ & & & & & & & & & & \\
\hline $\begin{array}{l}\text { Place of birth/time since } \\
\text { UK entry to TB } \\
\text { diagnosis }\end{array}$ & & & & $<0.0001$ & & & $<0.0001$ & & & & & & & & & \\
\hline UK-born & $4503(17.31)$ & 4.09 & $3.83-4.37$ & & 2.11 & $1.88-2.39$ & & & & & & & & & & \\
\hline $\begin{array}{l}\text { Non-UK-born, entered } \\
<5 \text { years before } \\
\text { diagnosis }\end{array}$ & 1226 (4.87) & Ref. & & & Ref. & & & & & & & & & & & \\
\hline $\begin{array}{l}\text { Non-UK-born, entered } \\
\geqslant 5 \text { years before } \\
\text { diagnosis }\end{array}$ & 1747 (6.99) & 1.47 & $1.36-1.58$ & & 1.46 & $1.33-1.61$ & & & & & & & & & & \\
\hline $\begin{array}{l}\text { Site of disease/sputum- } \\
\text { smear status }\end{array}$ & & & & $<0.0001$ & & & $<0.0001$ & & & & & & & & & \\
\hline Pulmonary/SS+ & 1980 (10.52) & 1.62 & $1.52-1.72$ & & 1.45 & $1.31-1.61$ & & & & & & & & & & \\
\hline $\begin{array}{l}\text { Pulmonary/SS- or } \\
\text { unknown }\end{array}$ & $4418(12.71)$ & 2.00 & $1.90-2.11$ & & 0.74 & $0.64-0.84$ & & & & & & & & & & \\
\hline Extrapulmonary & 2666 (6.78) & Ref. & & & Ref. & & & & & & & & & & & \\
\hline Previous TB & & & & $<0.0001$ & & & $<0.0001$ & & & & & & & & & \\
\hline Yes & $832(12.67)$ & 1.44 & $1.33-1.56$ & & 1.18 & $1.08-1.29$ & & & & & & & & & & \\
\hline No & $6402(9.14)$ & Ref. & & & Ref. & & & & & & & & & & & \\
\hline
\end{tabular}

SS+: sputum smear positive; SS-: sputum smear negative. 
In doing so, findings from this study contribute important information for clinical and public health action to improve TB control in the UK and in other low incidence countries with a comparable TB epidemiology moving towards the elimination phase $[5,6]$. As the epidemic in many low incidence countries changes from one affecting particular risk groups, misdiagnosis will become an increasingly important issue. Further progress towards the ambitious goals of the End TB Strategy and the elimination of TB [7] will also require more effective TB prevention among vulnerable and TB high-risk groups [8], and addressing the social and structural determinants of TB [9].

@ERSpublications

The changing epidemiology of TB in low incidence settings has implications for TB diagnosis and therefore elimination http://ow.ly/KN6Vq

Debora Pedrazzoli $^{1,2}$, Ibrahim Abubakar ${ }^{2,3}$, Helena Potts ${ }^{4}$, Paul R. Hunter ${ }^{4}$, Michelle E. Kruijshaar ${ }^{5}$, Onn Min Kon ${ }^{6}$ and Jo Southern ${ }^{1}$

${ }^{1}$ TB Modelling Group, TB Centre and CMMID, Faculty of Epidemiology and Population Health, London School of Hygiene and Tropical Medicine, London, UK. ${ }^{2}$ TB Section, Centre for Infectious Disease Surveillance and Control, Public Health England, London, UK. ${ }^{3}$ Centre for Infectious Disease Epidemiology, Research Department of Infection and Population Health, University College London, London, UK. ${ }^{4}$ Norwich Medical School, University of East Anglia, Norwich, UK. ${ }^{5}$ Centre for Lysosomal and Metabolic Diseases, Sophia Children's Hospital, Erasmus MC University Medical Centre, Rotterdam, The Netherlands. ${ }^{6}$ Chest and Allergy Clinic, St Mary's Hospital, Imperial College Healthcare NHS Trust, London, UK.

Correspondence: Debora Pedrazzoli, Faculty of Epidemiology and Population Health, London School of Hygiene and Tropical Medicine, Keppel Street, London, WC1E 7HT, UK. E-mail: debora.pedrazzoli@lshtm.ac.uk

Received: Nov 212014 | Accepted after revision: March 08 2015 | First published online: April 162015

Conflict of interest: None declared.

\section{References}

1 Abubakar I, Lipman M, Anderson C, et al. Tuberculosis in the UK - time to regain control. BMJ 2011; 343: d4281.

2 Story A, Murad S, Roberts W, et al. Tuberculosis in London: the importance of homelessness, problem drug use and prison. Thorax 2007; 62: 667-671.

3 Kruijshaar M, Abubakar I. Increase in extra-pulmonary tuberculosis in England and Wales 1999-2006. Thorax 2009; 64: 1090-1095.

4 Davies PDO, Pai M. The diagnosis and misdiagnosis of tuberculosis. Int J Tuberc Lung Dis 2008; 12: 1226-1234.

5 Lonnroth K, Migliori GB, Abubakar I, et al. Towards tuberculosis elimination: an action framework for low-incidence countries. Eur Respir J 2015; 45: 928-952.

6 D'Ambrosio L, Dara M, Tadolini M, et al. Tuberculosis elimination: theory and practice in Europe. Eur Respir J 2014; 43: 1410-1420.

7 World Health Organization. The End TB Strategy. Global Strategy and Targets for Tuberculosis Prevention, Care and Control after 2015. Geneva, World Health Organization, 2015. www.who.int/tb/post2015_TBstrategy.pdf?ua=1

8 Diel R, Loddenkemper R, Zellweger JP, et al. European Forum for TB Innovation. Old ideas to innovate tuberculosis control: preventive treatment to achieve elimination. Eur Respir J 2013; 42: 785-801.

9 Reeves A, Basu S, McKee M, et al. Social protection and tuberculosis control in 21 European countries, 1995-2012: a cross-national statistical modelling analysis. Lancet Infect Dis 2014; 14: 1105-1112.

\section{Fluoroquinolone use delays tuberculosis treatment despite immediate mycobacteriology study}

To the Editor:

Despite its excellent activity against Mycobacterium tuberculosis [1], empirical fluoroquinolone (FQ) therapy has been associated with delayed initiation of appropriate treatment [2-4] and acquired resistance $[5,6]$ in tuberculosis (TB) patients presenting as community-acquired pneumonia (CAP). A previous study conducted in intensive care unit revealed immediate mycobacteriology study may possibly prevent the delay in anti-TB treatment [7]. However, this hypothesis has not been confirmed. 